\section{Fruit Characteristics and Sensory Attributes of an Ideal Sweet Cherry}

\author{
Frank Kappel, Bob Fisher-Fleming, and Eugene Hogue \\ Agriculture and Agri-Food Canada, Research Centre, Summerland, B.C. VOH \\ 1ZO, Canada
}

Additional index words. Prunus avium, sensory evaluation, Just Right scale, hedonic scale, fruit weight, color, firmness, sweetness

\begin{abstract}
The relationship between the objective assessment of analytical measures of sweet cherry (Prunus avium $\mathbf{L}$.) fruit quality and the corresponding sensory panel rating was studied. The optimum size, based on average fruit weight, for sweet cherries was 11 to $12 \mathrm{~g}$. A nine-row or 29- to 30-mm-diameter sweet cherry would be the equivalent industry standard. When two separate panels were conducted with overlapping samples, panelists had similar results for optimum fruit size. The optimum color is represented by the \#6 color chip of the prototype of the Centre Technique Interprofessionnel des Fruits et Légumes (CTIFL) scale (\#5 in new commercial CTIFL chart). A fruit firmness between 70 and 75 using a Shore Instrument durometer was considered optimum. Minimum soluble solids concentration (SSC) for sweet cherries was between $17 \%$ and $19 \%$ and optimum pH of the juice was 3.8. The optimum sweet-sour balance was between 1.5 and $2(\mathrm{SSC} / \mathrm{ml} \mathrm{NaOH})$.
\end{abstract}

In British Columbia, the main sweet cherry cultivars are 'Lambert' and 'Van', whereas 'Bing', 'Sam', and 'Stella' are considered minor commercial cultivars (Lane, 1988). In sweet cherry growing regions of the western United States, 'Bing' is the major cultivar (Roper and Rom, 1990). Recently, there has been much interest in new sweet cherry cultivars from around the world to fill various marketing niches by extending the maturity season and to solve production problems, such as rain-induced cracking, self-incompatibility, and fruit softness.

What constitutes a "good" sweet cherry cultivar is open to debate, but fruit size, firmness, and sweetness are all considered important fruit quality traits (Proebsting, 1992; Vittrup Christensen, 1995; Ystaas and Frøynes, 1990). The objective of this study was to develop analytical or instrumental standards for fruit size, color, firmness, and sweetness that can be used to identify sweet cherry cultivars that will gain consumer acceptance. These standards can then be used in a cultivar introduction program to screen unsuitable cultivars. Also, these criteria can be used to screen breeding selections in a sweet cherry breeding program to improve the efficiency of the selection process.

Received for publication 2 Oct. 1995. Accepted for publication 6 Mar. 1996. Summerland Research Centre contribution no. 950. We acknowledge the financial assistance of the Okanagan Valley Tree Fruit Authority to carry out this work. We thank M. Cliff and M. Dever for their advice and M. Bouthillier and R. MacDonald for their technical assistance. The cost of publishing this paper was defrayed in part by the payment of page charges. Under postal regulations, this paper therefore must be hereby marked advertisement solely to indicate this fact.
Sensory panels were conducted during the 1992 and 1993 sweet cherry seasons at the Research Centre, Summerland, B.C.Cultivars and selections were chosen to provide a range of sensory attributes so that relationships between analytical measurements and the corresponding attributes could be developed. For all tasting panels, a subsample of fruit was used for the panels and a matching subsample was used to measure soluble solids concentration (SSC), $\mathrm{pH}$, and titratable acidity (TA). Also, for all tasting panels, all fruit were visible when sampled. SSC was determined on a ground composite sample using an ABBE Mark II digital refractometer (AO Scientific Instruments, Keene, N.H.). A 15-ml juice sample was titrated with $0.1 \mathrm{~N} \mathrm{NaOH}$ to $\mathrm{pH} 8.1$ and TA was expressed as milligrams of malic acid/100 $\mathrm{ml}$ of juice. Firmness of individual fruit was assessed using a hand-held durometer (Shore Instrument, Jamaica, N.Y.). Skin color of individual fruit was assessed using the color chart developed by the Centre Technique Interprofessionnel des Fruits et Légumes (CTIFL) (Planton and Edin, 1995). This prototype chart provides a range of red color chips numbered from 1 to 8 , with 1 being a light pink-red and 8 being a very dark red. The CTIFL chart allowed for a stepwise progression of color from a light pink-red cherry to a very dark, almost black sweet cherry, and color categories could be duplicated at various times throughout the study. Since this work was completed, a new chart has been released for use by the industry in France.

Panelists were recruited from the area by advertising in local papers, radio, and television stations and were paid a stipend. All panelists participated in an introductory session to familiarize them with the project goals, collect pertinent information about them, increase their awareness of their senses, and

\section{Materials and Methods}

educate them in evaluation techniques. In some cases, the panelists helped develop the protocol used in the panels, such as designing forms and developing anchor words.

Fruit size evaluation, 1992. We are expressing size in terms of fruit weight. Seven groups of sweet cherries were selected to provide an equally spaced range of weights (6.8 to $16.6 \mathrm{~g}$ ) and seven cherries per weight category were displayed on a white tray. Twenty-seven panelists evaluated fruit size using the 7-point Just Right (JR) scale (Meilgaard et al., 1991), where $1=$ too small; $4=\mathrm{JR}$; and $7=$ too large.

1993. Two groups of weight categories were evaluated by 22 panelists on 13 July. The small fruit ranged from $7.2 \mathrm{~g}$ average fruit weight to $12.4 \mathrm{~g}$. The large group ranged from 10.4 to $15.3 \mathrm{~g}$. The three largest categories in the small group overlapped with the three smallest categories of the large group to determine whether the range of cherries presented affected the panelists' judgments. The JR scale was used again.

Color evaluations, 1992. Fruit of similar size and shape were separated into seven color categories designated 2 to 8 using the CTIFL Sweet Cherry Color Chart. For the first panel on 9 July, 27 panelists used the 7-point JR scale to assess fruit color. For this scale $1=$ too pale; $4=\mathrm{JR}$; and $7=$ too intense. The second panel of 28 people on 16 July used the 7-point hedonic scale, where $1=$ dislike very much; 2 $=$ dislike moderately $; 3=$ dislike slightly $; 4=$ neither dislike nor like; $5=$ like slightly; $6=$ like moderately; and $7=$ like very much. For both panels, seven cherries for each color category were displayed on a white dish under natural light.

1993. Seven color categories were established using the CTIFL color chart. Each sample consisted of five sweet cherries displayed on a white dish in natural light. The color was averaged for each individual fruit sample and ranged from 4.5 to 8 with some overlap of adjacent samples. Twenty-one panelists evaluated the color using the JR scale, where $1=$ too red; $4=\mathrm{JR}$; and $7=$ too black.

Appearance evaluations, 1993. Fourteen samples in two groups were presented to 22 panelists to provide a broad range of fruit appearance. Each sample consisted of five sweet cherries displayed on a white dish in natural light. A 7-point hedonic scale was used for each attribute (fruit size and color), using the scale described above. Each attribute was assessed separately. Fruit weight ranged from an average of 8.8 to $15.2 \mathrm{~g}$. Fruit color was averaged for each individual sample using the CTIFL color chart and ranged from 4.5 to 8 .

Sensory evaluations, 1992. Three separate panels evaluated various sweet cherry cultivars and selections using the JR scale for the attributes texture (fruit firmness), flavor impact, and sweet-sour balance. The fruit were harvested 24 June, 1 July, and 8 July and stored at $0 \mathrm{C}$ until evaluation on 2, 9, and 16 July, respectively. The fruit were removed the day before the evaluations and stored at 20C. The 7-point JR scale was used, where the anchors were as follows: texture: $1=$ too soft, $4=\mathrm{JR}$, and $7=$ too firm; flavor impact: $1=$ too bland, 
$4=\mathrm{JR}$, and $7=$ too intense; and sweet-sour balance: $1=$ too sour, $4=\mathrm{JR}$, and $7=$ too sweet. The number of panelists were 18,27, and 28, respectively. We attempted, as much as possible, to standardize color and size, and stems were removed from all the fruit. Objective measurements were taken, as described above, after the panels were completed each day.

1993. Fruit were harvested 4, 7, 11, 15, 18, 22 , and 25 July and stored at $0 \mathrm{C}$ for 5 days until panels were held. The number of panelists for each panel was 22, except on 13 July when it was 23. Each panel evaluated nine cultivars or selections. Panels 1 and 2; panels 3 and 4; and panels 5, 6, and 7 each had the same cultivars and selections. Cultivars were evaluated separately. Panelists assessed fruit firmness using the 7-point JR scale, where $1=$ too soft; $4=$ JR; and $7=$ too firm and sweet-sour balance using the 7-point JR scale, where $1=$ too sour; $4=$ JR; and $7=$ too sweet. The panelists also rated the overall acceptability using the 5-point hedonic scale, where $1=$ dislike very much; $2=$ dislike moderately; $3=$ neither dislike nor like; $4=$ like moderately; and $5=$ like very much. The 5-point scale was used because we used several scales during the same session and were attempting to avoid complications by not having two 7-point scales. Objective measurements were taken as described above after the panels were completed each day.

Statistics. The relationship between the analytical measures associated with a particular sensory attribute or a fruit characteristic and the corresponding JR rating or hedonic assessment was calculated using regression analysis. The regressions were calculated using mean data.

\section{Results}

Except where noted, data for 1992 and 1993 evaluations were combined because of similarities of the regression equations.

Fruit size. Optimum size, using the overall regression equation and a JR rating of 4, was equivalent to $11.6 \mathrm{~g}$ average fruit weight (Fig. 1A). This corresponds to about a nine-row fruit, a commercial size designation. Similar results were obtained in 1992 and 1993. Also, in 1993 two groups of fruit were used where the three largest categories in the small group overlapped with the three smallest categories of the large group. The groups also overlapped in the JR assessment made by the panelists, having similar slopes when they were analyzed separately. With the 7-point hedonic rating scale, the relationship between fruit size and rating scale was curvilinear (Fig. 1B) and peaked around 11- to 13-g average fruit weight. This relationship suggests that an increase in fruit size beyond the 11 to $13 \mathrm{~g}$ range would not increase the "liking" rating.

Fruit color. The JR rating and the color of the fruit as represented by the color chips of the CTIFL color chart were linearly related in both years (Fig. 2). The optimum color (JR = 4) was represented by the \#6 color chip (Fig. $2 \mathrm{~A})$. This color is very similar to the \#6 comparator (Okanagan Federated Shippers, Kelowna, B.C.). Fruit color and the hedonic
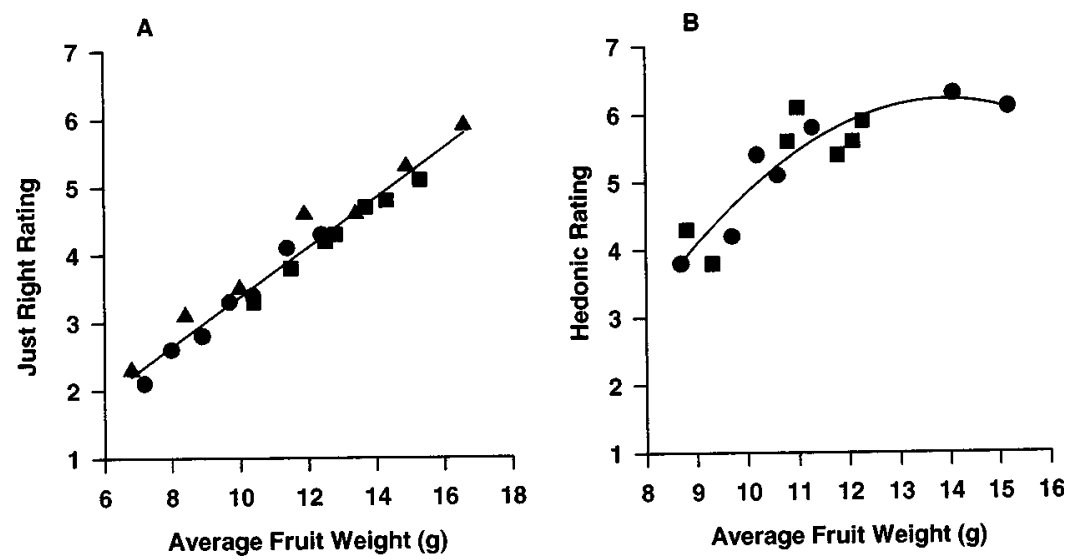

Fig. 1. (A) Size assessments, as expressed by average weight, of sweet cherry fruit in 1992 (A) and 1993 [(-) group 1 and (ロ) group 2]. Relationship between average fruit weight in 1992 and 1993 and the Just Right ratings, with $\mathrm{y}=-0.29( \pm 0.19)+0.37( \pm 0.02) \mathrm{x}$ and $r^{2}=0.96$ and $P=0.0001$. (B) Average hedonic rating for fruit size in 1993, $(\bullet)$ group 1 and $(\mathbf{\square})$ group 2 . Regression equation is $y=-10.65( \pm 3.65)+$ $2.42( \pm 0.63) \mathrm{x}-0.09( \pm 0.03) \mathrm{x}^{2}$ and $r^{2}=0.83$ and $P=0.0001$. Numbers in parentheses are standard errors of the estimate.
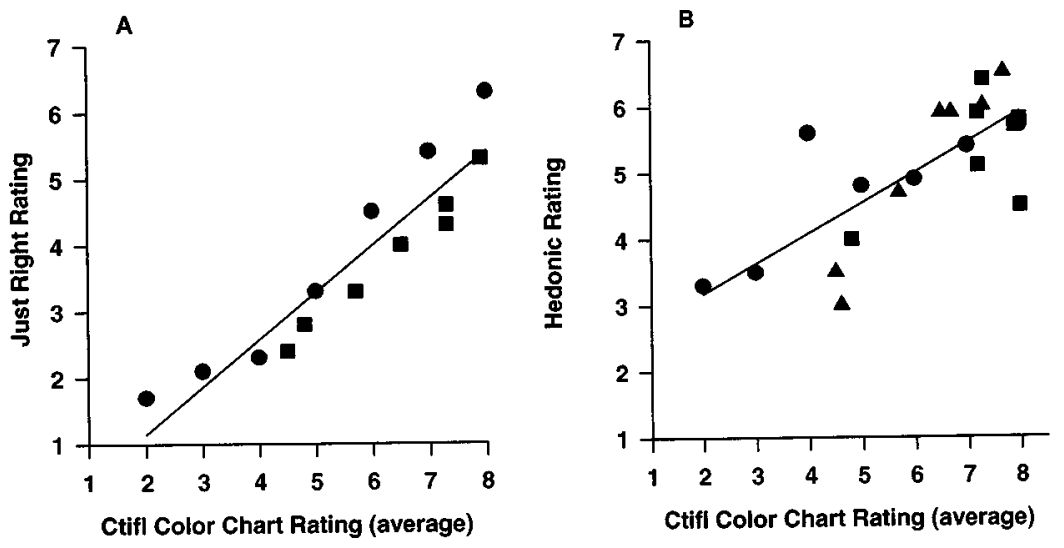

Fig. 2. (A) Sweet cherry fruit color assessments using the Centre Technique Interprofessionnel des Fruits et Légumes (CTIFL) color charts and the Just Right ratings in $1992(\boldsymbol{O})$ and 1993 (口). Regression equation is $\mathrm{y}=-0.27( \pm 0.46)+0.71( \pm 0.08) \mathrm{x}$ and $r^{2}=0.87$ and $P=0.0001$. (B) Average hedonic rating for fruit color in $1992(\boldsymbol{\bullet})$ and 1993 ( $\mathbf{\square}$, group 1; $\boldsymbol{\Delta}$, group 2) using the CTIFL color charts. Regression equations are $\mathrm{y}=2.27( \pm 0.58)+0.45( \pm 0.09) \mathrm{x}$ and $r^{2}=0.57$ and $P=0.0001$. Numbers in parentheses are standard errors of the estimate.

rating were linearly related in 1992 and 1993 (Fig. 2B).

Fruit firmness. Within the range of fruit firmness used, measured firmness and JR rating by the panelists were linearly related (Fig. 3 ). The optimum firmness is in the range of 70 to 75 on the hand-held durometer, using the equation developed for the combined 1992 and 1993 data.

Fruit sweetness and flavor. The sweetsour balance $(\mathrm{SSC} / \mathrm{ml} \mathrm{NaOH})$ and the JR rating for fruit sweetness were closely related (Fig. 4A). The optimum ratio with JR $=4$ is in the range of 1.5 to 2 . The relationship between sweet-sour balance and overall acceptability of the fruit was curvilinear and appears to confirm the results using the JR scale (Fig. 4B).

In 1992 there was a significant curvilinear relationship between flavor impact and SSC (Fig. 5A) or TA (Fig. 5B). Both curves appear to approach the JR value of 4, suggesting that the panelists did not consider the fruit flavor too intense as SSC or TA increased. Fruit pH was negatively and linearly related to flavor impact, suggesting that as fruit became less acidic, panelists judged it to be increasingly bland (Fig. 5C). The optimum $\mathrm{pH}(\mathrm{JR}=4)$ was 3.76 .

The overall acceptability (5-point hedonic scale) was linearly related to the SSC of the fruit in 1993 (Fig. 6). As SSC increased, so did the favorable rating of the fruit. Using the hedonic value of 3 for this scale (moderately like) and the regression equation suggests that the minimum SSC value for sweet cherries should be $19.5 \%$.

\section{Discussion}

Panelist response to fruit size was similar for the two years. Optimum fruit size was consistent even when the optimum was at either end of the range presented. This observation increases confidence in the results, because the panelists did not appear to be influenced by the size range presented. The different response between the two scales (linear for 


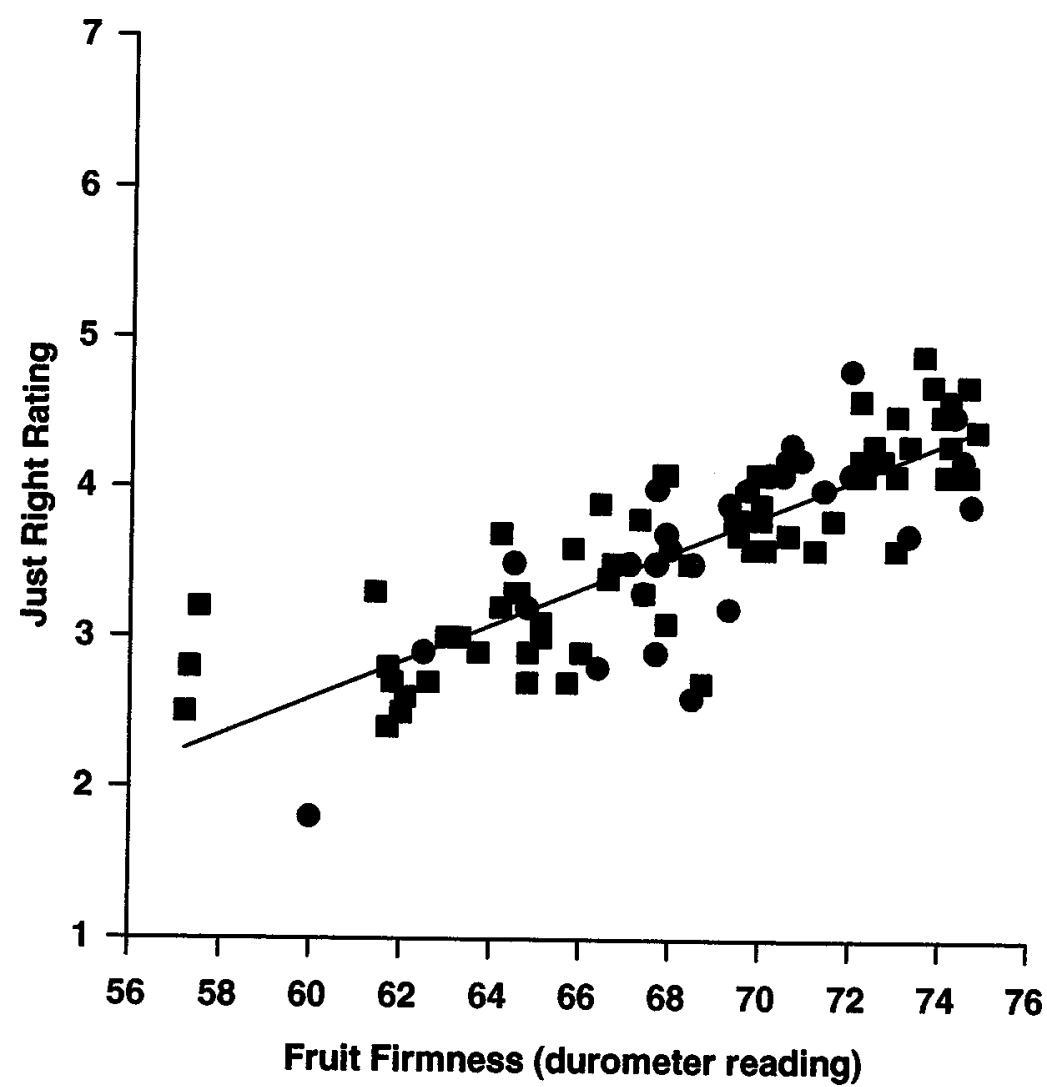

Fig. 3. Firmness assessment (durometer readings) of sweet cherry fruit. Relationship between fruit firmness in $1992(\mathbf{)})$ and $1993(\square)$ and the Just Right rating with $\mathrm{y}=-4.75( \pm 0.60)+0.12( \pm 0.01) \times$ and $r^{2}=0.68$ and $P=0.0001$. Numbers in parentheses are standard errors of the estimate.

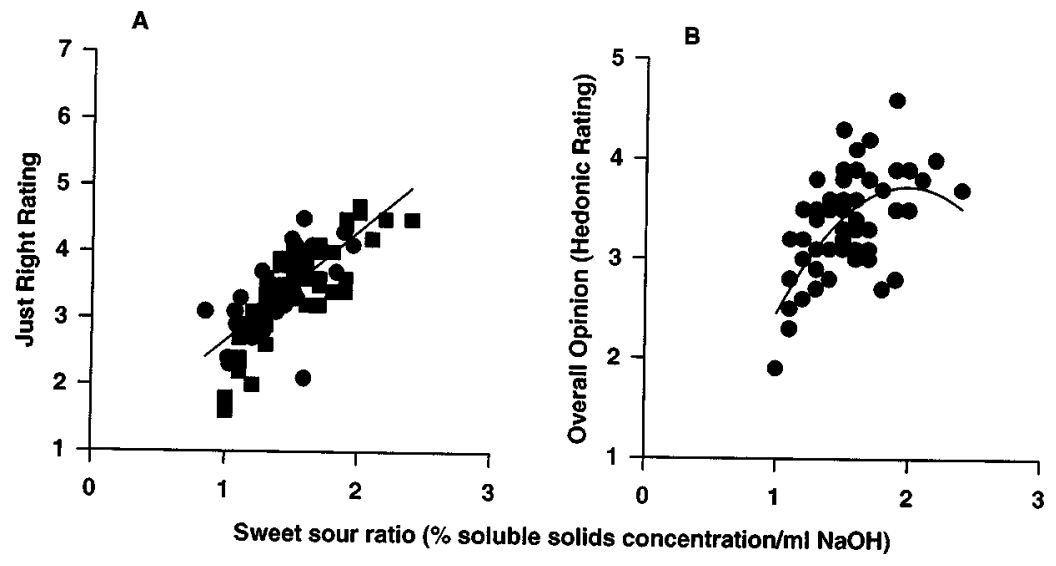

Fig. 4. (A) Relationship between sweet-sour balance of sweet cherry fruit and Just Right rating in 1992 (()) and $1993(\square)$ with $y=1.02( \pm 0.22)+1.65( \pm 0.15) \mathrm{x}$ and $r^{2}=0.57$ and $P=0.0001$. (B) Overall opinion of the flavor of sweet cherry using the hedonic scale. Relationship between sweet-sour balance and hedonic rating with $\mathrm{y}=-1.42( \pm 1.14)+5.18( \pm 1.44) \mathrm{x}-1.30( \pm 0.44) \mathrm{x}^{2}$ and $r^{2}=0.39$ and $P=0.0001$. Numbers in parentheses are standard errors of the estimate.

JR and curvilinear for hedonic) suggests the same optimum fruit size. The observations from the JR scale suggest the optimum fruit size to be equivalent to $\approx 12 \mathrm{~g}$, whereas the results from the hedonic scale suggest the optimum to be between 11 and $13 \mathrm{~g}$. Large fruit size is a major contributor to the perception of a high-quality sweet cherry (Facteau, 1988; Proebsting, 1992; Vittrup Christensen, 1995). The standard sweet cherry cultivar in the western United States is 'Bing', described as a "heavy yielder with large fruit, some more than an inch $(25 \mathrm{~mm})$ in diameter" (Roper and
Anecdotal reports suggest that consumers attempt to use color to determine maturity and freshness (days from harvest). Dark red was preferred over a lighter red, perhaps because of the perception that a darker sweet cherry is sweeter. A sweet cherry that is too dark may be considered overripe or not fresh. Most sweet cherries darken as they ripen (Proebsting and Murphey, 1987). Therefore, fruit could be harvested at the most appropriate color for the intended market. Cultural practices affecting leaf area may also impact color development. Roper and Loescher (1987) found that as leaf area increased fruit color increased in color grades ranging from pink to mahogany.

The results from the JR rating scale suggest that sweet cherries matching the \#6 color chip were considered optimum, whereas the work with the hedonic scale suggests that, as fruit darken, they become more acceptable. A possible interpretation is that the JR rating provides the minimum acceptable color, which, in this case, is fruit color matching the \#6 color chip. The \#6 CTIFL prototype color chip is similar to the \#6 color comparator (Okanagan Federated Shippers), which is used by the industry and the color chip \#187B of the Royal Horticultural Society Colour Chart. Since this work was done, a commercial version of the color chart has been developed and released to the industry by CTIFL. In the new chart, the range of colors is from 1 to 7 . The \#6 chip in the prototype is equivalent to the \#5 chip in the new commercial chart.

A durometer was used in this study to measure fruit firmness. Proebsting and Murphey (1987) stated that the instrument was unreliable because of the variability associated with it. However, in our work, we found a very good relationship between the instrument readings and the panelists' perception of fruit firmness. We, therefore, consider it a useful tool to give a reasonable indication of fruit firmness. Fruit firmness is a combination of skin and flesh strength and appears to affect consumer acceptance and shelf life (Brown and Bourne, 1988). Our work did not attempt to identify the most important quality traits, but fruit firmness is considered extremely important by the industry.

Sweet cherries obviously must be sweet to be considered of high quality. Drake and Fellman (1987) indicate that 'Rainier' cherry must have at least $16 \%$ SSC to be considered acceptable. Our work suggests a minimum SSC of $\approx 15 \%$ for sweet cherries. We also demonstrated a close relationship between the sweet-sour balance and the sensory rating for fruit sweetness, which suggests that TA is important for the perception of fruit sweetness and also flavor impact. Cliff et al. (1996) demonstrated that "liking" was related to the sum of SSC and TA. Without the right balance, the fruit would be judged bland. SSC increases as fruit mature (Drake and Fellman, 1987; Proebsting and Murphey, 1987), and is affected by leaf area per fruit (Roper and Loescher, 1987) and location of the fruit within the tree (Drake and Fellman, 1987).

An "ideal" red sweet cherry for the general North American market can be described by 

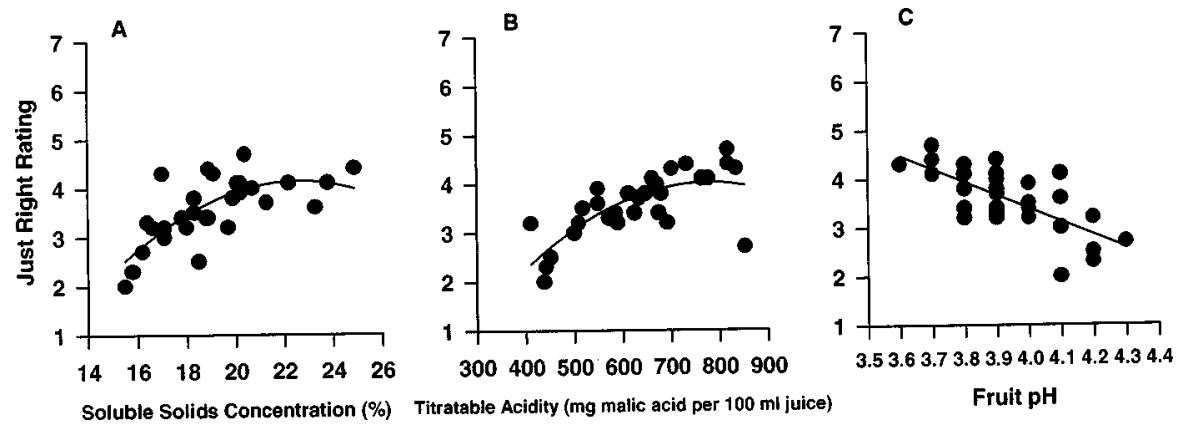

Fig. 5. Flavor impact assessments of sweet cherry fruit. (A) Relationship between soluble solids concentration and Just Right rating with $\mathrm{y}=-12.22( \pm 5.10)+1.45( \pm 0.52) \mathrm{x}-0.03( \pm 0.01) \mathrm{x}^{2}$ and $r^{2}=0.51$ and $P=0.0001$. (B) Relationship between titratable acidity and Just Right rating with $y=-3.38( \pm 2.03)+$ $0.02( \pm 0.007) \mathrm{x}-0.00001( \pm 0.000005) \mathrm{x}^{2}$ and $r^{2}=0.55$ and $P=0.0001$. (C) Relationship between $\mathrm{pH}$ and Just Right rating with $\mathrm{y}=14.2( \pm 1.95)-2.71( \pm 0.50) \mathrm{x}$ and $r^{2}=0.52$ and $P=0.0001$. Numbers in parentheses are standard errors of the estimate.

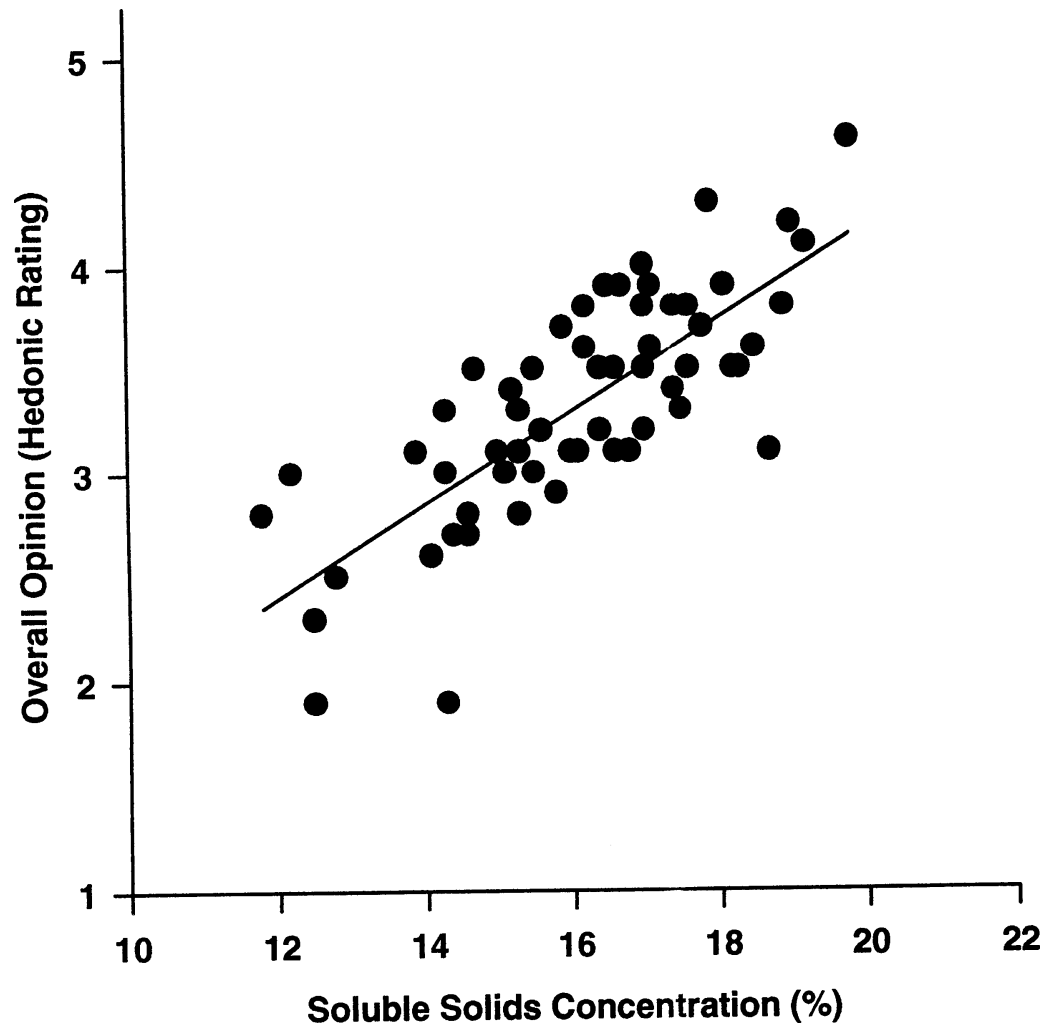

Fig. 6. Overall opinion of the flavor of sweet cherry fruit using the hedonic scale. Relationship between soluble solids concentration and hedonic rating with $\mathrm{y}=-0.28( \pm 0.39)+0.22( \pm 0.02) \mathrm{x}$ and $r^{2}=0.59$ and $P=0.0001$. Numbers in parentheses are standard errors of the estimate.

the following characteristics: a fruit size equivalent to 11 to $12 \mathrm{~g}$ (average fruit weight) (about a nine-row cherry or 29 to $30 \mathrm{~mm}$ in diameter), a red color matching the \#6 color chip (CTIFL prototype color chart or \#5 of the new commercial CTIFL chart), a firmness between 70 and 75 on the hand-held durometer, a SSC of $17 \%$ to $19 \%$, a sweet-sour balance of 1.8 to 2
( $\mathrm{SSC} / \mathrm{ml} \mathrm{NaOH})$, and a $\mathrm{pH}$ of $\approx 3.8$. Opinions of consumers and panelists living close to this major horticultural production area of Canada may not reflect those throughout North America. Nevertheless, these values and procedures can be used to screen new cultivars and breeding selections for their potential acceptability, or by growers as targets to ensure that cultural practices favorably affect fruit quality. Sweet cherry selections and cultivars not fitting these characteristics still could become valuable introductions to meet niche markets or specific markets, such as the Asian markets where very sweet, low-acid fruit with a light flesh color may be more suitable.

\section{Literature Cited}

Brown, S.K. and M.C. Bourne. 1988. Assessment of components of fruit firmness in selected sweet cherry genotypes. HortScience 23:902-904.

Cliff, M.A., M.C. Dever, J.W. Hall, and B. Girard. 1996. Development and evaluation of multiple regression models for prediction of cherry cultivar liking. Food Res. Intl. 29:(In press).

Drake, S.R. and J.K. Fellman. 1987. Indicators of maturity and storage quality of 'Rainier' sweet cherry. HortScience 22:283-285.

Facteau, T. 1988. Improving cherry quality. Proc. Pacific Northwest Cherry Production Shortcourse, Washington State Univ., Pullman. p. 216-230.

Lane, D. 1988. Variety trends in British Columbia. Proc. Pacific Northwest Cherry Production Shortcourse. Washington State Univ., Pullman. p. 69-71.

Meilgaard, M., G.V. Civille, and B.T. Carr. 1991. Sensory evaluation techniques. 2nd ed. CRC Press, Boca Raton, Fla. p. 217-218.

Planton, G. and M. Edin. 1995. Cerise: Un code couleur pour une meilleure qualité. Infos-Ctifl 110:9.

Proebsting, E. 1992. Pruning for higher quality cherries, crop regulation. Proc. Wash. State Hort. Assn. p. 314-315.

Proebsting, E.L. and A.S. Murphey. 1987. Variability of fruit quality characteristics within sweet cherry trees in central Washington. HortScience 22:227-230.

Roper, T.R. and W.H. Loescher. 1987. Relationships between leaf area per fruit and fruit quality in 'Bing' sweet cherry. HortScience 22:12731276.

Roper, T.R. and C.R. Rom. 1990. 'Bing' sweet cherry. Fruit Var. J. 44:106-108.

Vittrup Christensen, J. 1995. Evaluation of fruit characteristics of 20 sweet cherry cultivars. Fruit Var. J. 49:113-117.

Ystaas, J. and O. Frøynes. 1990. An evaluation based on the field performance of 38 cultivars of sweet cherries. Norsk Landbruksforsking 4:115126. 